society, or what Gladwell calls social epidemics, but the resemblance ends there. Gladwell's book is fluffy and full of entertaining anecdotes, but is often unconvincing. Ball's is substantial, impeccably researched and generally more persuasive. For anyone who would like to learn about the intellectual ferment at the surprising junction of physics and social science, Critical Mass is the place to start.

Steven Strogatz is in the Center for Applied Mathematics and the Department of Theoretical and Applied Mechanics, Cornell University, Ithaca, New York 14853-1503, USA.

\section{Chemistry between man and insect}

\section{For Love of Insects}

by Thomas Eisner

Harvard University Press: 2003. 464 pp.

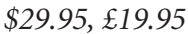

\section{Jeremy N. McNeil}

Chemical ecology, the study of how natural chemicals affect the interactions between organisms, has become a well-recognized discipline in the past 50 years. A number of remarkable scientists have moulded the field, many of whom mix their love of science with an appreciation for the arts and life in general, making them true Renaissance individuals. Thomas Eisner, author of For Love of Insects, is one such person: as well as a world-renowned scientist and teacher, he is an excellent photographer and talented musician.

For Love of Insects is not your typical biological text integrating information from the literature on a topic. Instead this book is a series of vignettes. Each of the ten chapters discusses a different chemical ecology project that Eisner and his colleagues have carried out over the past 40 years. The book is well written and beautifully illustrated with colour photographs, the majority taken by the author. I would strongly recommend this book for several reasons.

First, each chapter introduces the reader to different facets of the wonderful world of insects. We learn how many insects defend themselves by spraying aggressors with noxious secretions, how they hit their target, and how they keep themselves from suffering the effects of the compounds they deploy. We discover that insects may produce their own compounds or get them from their food. In some instances, females may receive them from males during mating, and the quantity of a male's defence compounds may determine whether he gets a mate.

Some insects defend themselves with their excrement, or disguise themselves with flower petals. Others adopt a strategy by

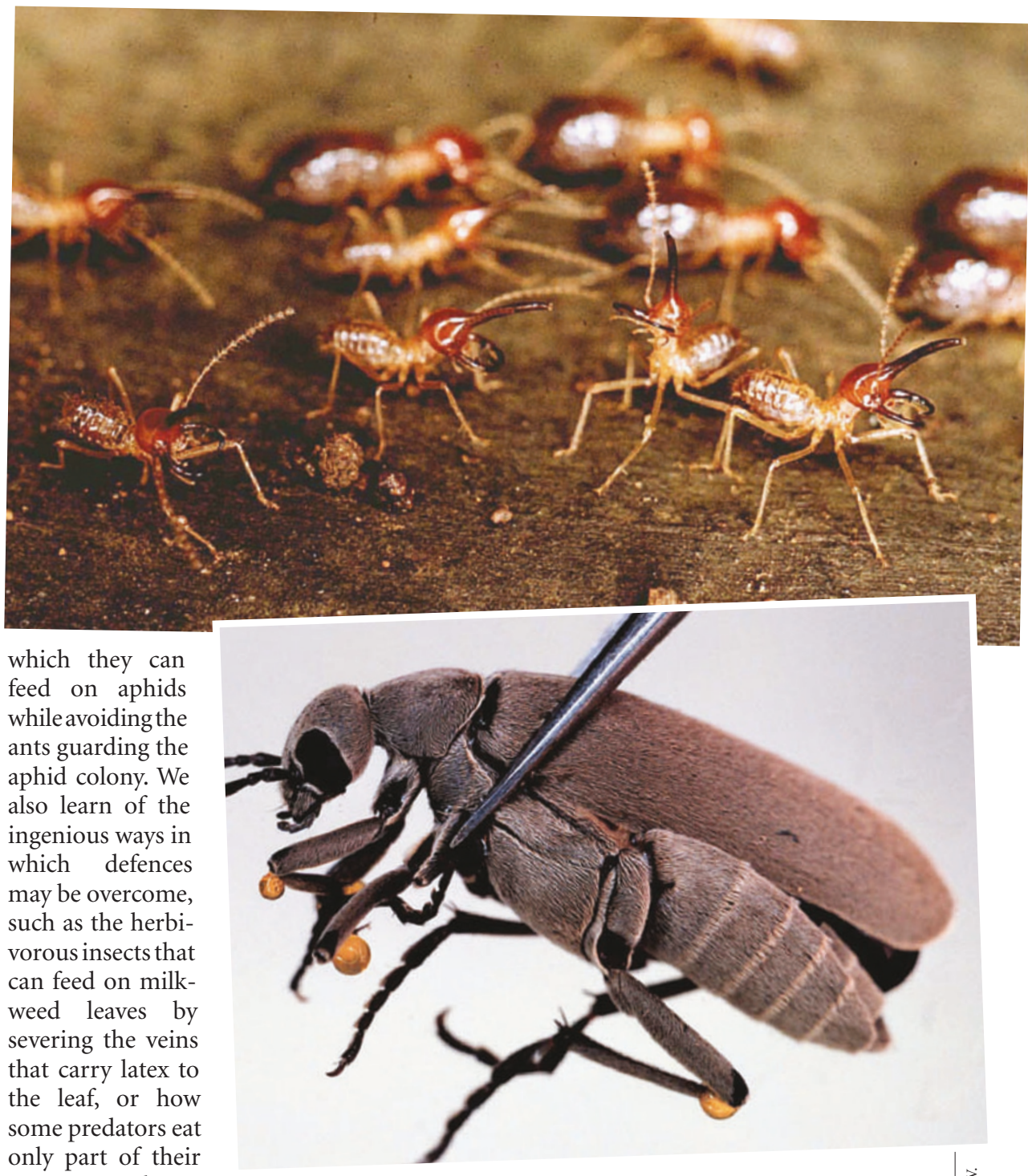

only part of their prey to avoid toxins. And if one is on the lookout for research projects, Eisner provides some pointers. For example, what is the role of the second soldier caste in the termite Nasutitermes exitiosus? Are blister beetles the only source of cantharidin, a defence chemical that is better known as the pre-Viagra Spanish fly, for cantharidiphilous insects?

Second, the author shows what is needed to produce first-class ecological research. Like Eisner, one must combine keen observation with a desire to understand the phenomena observed. Furthermore, one needs to design elegant and simple experiments to answer 'why?' and 'how?' questions. This underscores the importance of creative thinking - a timely reminder in the postgenomic world that good science is not just a matter of fancy equipment and sophisticated techniques.

Collaboration is another key ingredient. Eisner's research into the bombardier beetle, an insect that defends itself with boiling secretions - rather like a castle's soldiers pouring hot oil on the heads of besiegers spanned more than 30 years. He credits his graduate students Daniel Aneshansley and
Jeff Dean and 17 others who identified and acquired biological material, provided insights into chemical defences and the role of benzoquinones in particular, and worked out how to photograph the spectacular defensive behaviour.

Two collaborators stand out. Eisner has a long-standing association with chemist Jerry Meinwald, who identified many of the compounds involved in the interactions observed. The other is his wife, Maria Eisner, who took the excellent scanning electron micrographs found in this book and in many of their publications. Both share Eisner's love of music, and I have heard meetings.

Throughout the text one is reminded of the pleasure that the author derives from discovery. Anyone reading this book will themselves embark upon a journey of discovery and come to share, if only at arm's length, Tom's love of insects and the wonders of nature.

Jeremy N. McNeil is in the Department of Biology, University of Western Ontario, London,

Ontario N6A 5B7, Canada. Tom and Jerry perform at several scientific 